\section{ACKNOWLEDGEMENTS}

I would like to acknowledge the comments and additions suggested by members of the Environmental Health Branch, NSW Health, and by journal reviewers.

\section{REFERENCES}

1. Cole BL, Wilhelm M, Long PV, Fielding JE, Kominski G, Morgenstern H. Prospects for health impact assessment in the United States: New and improved environmental impact assessment or something different? Journal of Health Politics, Policy \& Law 2004; 29(6): 1153-86.

2. Beder S. Early environmentalists and the battle against sewers in Sydney, Royal Australian Historical Society Journal 1990; 76(1): 27-44.

3. Legislative Council. General Purpose Standing Committee. Report on Inquiry into Northside Storage Tunnel-Scotts Creek Vent. Parliamentary paper No. 453, 2000.

4. Legislative Council. General Purpose Standing Committee No. 5. Inquiry into the M5 East Tunnel. Sydney: New South Wales Parliament, 2002.
5. Krieger N, Northridge M, Gruskin S, Quinn M, Kriebel D, Davey Smith G, et al. Assessing health impact assessment: Multidisciplinary and international perspectives. J Epidemiol and Community Health 2003; 57: 659-62.

6. Hunter D. Ch 2: The relationship between health and health care. In Public Health Policy. Polity Press, 2003.

7. Landy MK, Roberts MJ, Thomas SR. The Environmental Protection Agency: Asking the wrong questions from Nixon to Clinton. New York: Oxford University Press, 1994.

8. Vineyard to Rouse Hill electricity upgrade-Independent report to examine the cost of the options for the upgrade. November 2004. Maunsell Australia Pty Ltd. Available from the Integral energy website at: www.integral.com.au/index. cfm?objectid=B05033AF-8028-BBAF-106908876245FC3A. Accessed 9 November 2005.

9. Agency for Toxic Substances and Disease Register. Public Health Assessments. Available at www.atsdr.cdc.gov/HAC/ PHA/, accessed 9 November 2005. 용

\title{
BUILDING AN EQUITY FOCUS IN HEALTH IMPACT ASSESSMENT
}

\author{
Rosemary Aldrich \\ Newcastle Institute of Public Health \\ University of Newcastle
}

\section{Mary Mahoney \\ Health Impact Assessment Research Unit \\ Deakin University, Melbourne}

Elizabeth Harris and Sarah Simpson*

Centre for Health Equity Training Research

and Evaluation

University of New South Wales

\section{Jenny Stewart-Williams}

Newcastle Institute of Public Health

University of Newcastle

Health impact assessment (HIA) is underpinned by equity as a core value in its conventions and objectives. ${ }^{1}$ However, there has been debate on whether an explicit assessment of impacts on health inequalities is required to characterise the differential distribution of impacts on health that might result from a policy, planning or service decision. The Jakarta Declaration ${ }^{2}$ and the United Kingdom's Independent Inquiry into Inequalities in Health ${ }^{3}$ called for equity-focused HIA and health inequalities impact assessment respectively (reiterated in the Bangkok Charter on Health Promotion in a Globalised World ${ }^{4}$ ). Attendees at a methodological seminar in 2001 in the United Kingdom assembled to discuss this issue decided, however, not to

\footnotetext{
* Sarah Simpson is currently employed by the World Health Organization in Geneva as Coordinator, Knowledge Networks, Commission on the Social Determinants of Health
}

differentiate health inequalities impact assessment from health impact assessment, instead concluding that every HIA should be a health inequalities impact assessment. ${ }^{5}$ Here we describe the development of a framework to guide equity-focussed HIA. Although the terms 'equity-focussed HIA' and 'health inequalities impact assessment' have been used synonymously in the literature, our collaboration used the term 'equity-focussed health impact assessment' instead of 'health inequalities impact assessment' as we wished to communicate that assessment of equity impacts was integral to HIA instead of a different process.

A review of 30 reports in the literature describing HIAs found that in practice few had explored equity impacts routinely or systematically, although some tools for health inequalities impact assessment had emerged. ${ }^{6}$ This reinforced our commitment to develop and pilot a framework for equity-focused health impact assessment that could be integral to the HIA, and used to explicitly consider the impacts on health inequalities that may result from a policy, plan or program.

In 2002, building on our work to develop policy-linked $\mathrm{HIA}^{7}$ and also on using socioeconomic evidence in health decision-making ${ }^{8}$, researchers from the Newcastle Institute of Public Health (NIPH), the Centre for Health Equity Training, Research and Evaluation (CHETRE) and the Health Impact Assessment Research Unit at Deakin University established the Australasian Collaboration for Health Equity Impact Assessment (ACHEIA). Together with our case-study partners and international advisors from the Cochrane and Campbell Collaborations and from 
HIA centres of excellence in the United Kingdom and New Zealand, we developed our framework. We then undertook the following five equity-focussed HIAs:

1. Healthy eating action policy (New Zealand Ministry of Health)

2. Dietary guidelines for older Australians (National Health and Medical Research Council)

3. Continuing education and professional development program for rural medical specialists (Royal Australasian College of Physicians)

4. Community funding program of health promotion grants and sponsorships (Australian Capital Territory Health Promotion Board)

5. Outpatient cardiac rehabilitation program (John Hunter Hospital, Newcastle, NSW).

Our framework differs from other tools for health inequalities or equity impact assessment in that the framework is embedded in conventional HIA. To each HIA step we added discrete questions or processes that triggered the exploration of critical equity considerations. A copy of the equity-focussed health impact assessment framework and reports on selected equity-focussed health impact assessments can be found at http://chetre.med. unsw.edu.au/files/EFHIA_Framework.pdf or www.deakin. edu.au/hia.

In undertaking the equity-focussed health impact assessments we found that we were able to:

- identify in a proposal its potential for unintended antiequity consequences

- generate recommendations that enhanced the potential for equity to be realised, potentially leading to a reduction in health inequalities.

Two examples illustrate the diverse settings in which equity-focussed health impact assessment might illuminate the health equity impacts of a proposal or plan. The Royal Australasian College of Physicians' equity-focussed health impact assessment found that while videoconferencing was widely regarded as having the potential to improve professional development for rural medical specialists, equity issues arose where access to videoconferencing was limited by technology. Where technology in rural areas does not keep pace with emerging Internet-based programs, a professional development program based on videoconferencing or internet programs may actually widen the educational gap between urban and rural specialists, with a flow-on effect to the communities they serve.

The equity-focussed health impact assessment of the New Zealand policy for healthy eating found that the policy development process had the potential to make it more difficult for certain groups to contribute to policy development, potentially resulting in a healthy eating policy that was limited in effectiveness for those groups, and particularly for Maori. As a result of the equity- focussed health impact assessment, recommendations were developed that focussed both on changing the approach to policy and strategy development within the New Zealand Ministry for Health, and on ensuring that equity issues were addressed as the healthy eating policy was implemented.

While equity remains a key principle of HIA, a more explicit analysis of the social and geographic distribution of the health impacts, and an assessment of the fairness of this distribution, is usually required. The equity-focussed health impact assessment framework is useful in these situations because it provides practitioners with guidance on how to systematically address equity in each step of HIA.

\section{ACKNOWLEDGEMENTS}

We wish to acknowledge the help provided by our casestudy partners and by the many advisors, researchers and health professionals who assisted in the development and piloting of the equity-focussed health impact assessment framework.

\section{REFERENCES}

1. European Centre for Health Policy. Health impact assessment: Main concepts and suggested approaches (Gothenburg Consensus paper). Brussels: ECHP and World Health Organization (Regional Office for Europe), 1999.

2. International Union for Health Promotion and Education. The Jakarta Declaration on leading health promotion into the 21st century. London: International Union for Health Promotion and Education, 1997.

3. Acheson D. Independent inquiry into inequalities in health. London: The Stationery Office, 1988. Available at www. official-documents.co.uk/document/doh/ih/chair/htm.

4. Global Conference on Health Promotion (2005). The Bangkok Charter for Health Promotion in a Globalised World. Bangkok, Thailand. Available at www.who.int/ healthpromotion/conferences/6gchp/bangkok_charter/en/

5. Douglas M, Scott-Samuel A. Addressing health inequalities in health impact assessment. J Epidemiol Community Health 2001; 55(7), 450-1. Accessed 9 October 2005.

6. Harris-Roxas B, Simpson S, Harris E. Equity focused health impact assessment: A literature review. Sydney: Centre for Health Equity Training Research and Evaluation (CHETRE) on behalf of the Australasian Collaboration for Health Equity Impact Assessment (ACHEIA), 2004. Available at http://chetre.med.unsw.edu.au/files/Harris-Roxas_B_(2004)_ Equity_Focused_HIA.pdf.

7. Mahoney M., Durham G. Health impact assessment: a tool for policy development in Australia. Melbourne: Health Impact Assessment Unit, Deakin University, 2002. Available at www. deakin.edu.au/hbs/hia/publications/HIA_Final_Report_2003. pdf Accessed 9 October 2005.

8. Aldrich R, Kemp L, Stewart Williams J, Harris E, Simpson $\mathrm{S}$, Wilson A et al. Using socioeconomic evidence in clinical practice guidelines. British Medical Journal 2003; 327 (29 Nov 2003), 1283-5. Available at http://bmj.bmjjournals. com/cgi/content/full/327/7426/1283. Accessed 9 October 2005. 